University of Wollongong

Research Online

Faculty of Social Sciences - Papers (Archive) Faculty of Arts, Social Sciences \& Humanities

$1-1-2016$

A systematic review of the relationship between psychological disorders or substance use and self-reported cognitive failures

Nicole Carrigan

University of Wollongong, nc957@uowmail.edu.au

Emma Barkus

University of Wollongong, ebarkus@uow.edu.au

Follow this and additional works at: https://ro.uow.edu.au/sspapers

Part of the Education Commons, and the Social and Behavioral Sciences Commons

Research Online is the open access institutional repository for the University of Wollongong. For further information contact the UOW Library: research-pubs@uow.edu.au 


\title{
A systematic review of the relationship between psychological disorders or substance use and self-reported cognitive failures
}

\author{
Abstract \\ Cognitive failures are errors in normal everyday functioning. Individuals with psychological disorders may \\ possess heightened vulnerability. We sought to review the literature on cognitive failures in psychological \\ disorders to determine the nature of this association, and whether failures relate to neuropsychological \\ performance. We also examine the relationship between cognitive failures and substance use since it is \\ relevant to everyday cognition and co-occurs in many psychological disorders. Methods: We conducted a \\ systematic review of self-reported cognitive failures in psychological disorders and substance use, \\ identifying 21 papers in total. Results: Papers identified studied trauma, mood, and anxiety disorders, and \\ schizophrenia. Substance use papers included nicotine, alcohol, cannabis, and ecstasy use. Cognitive \\ failures were increased in some but not all papers; the most consistent findings were for depression, \\ PTSD, and daily smokers of nicotine. Subjective failures did not correlate closely with neuropsychological \\ outcomes in any disorders. We were unable to discern distinct profiles of failures for each disorder; rather \\ they may reflect emotional dysregulation more broadly. Conclusions: The real world cognitive experiences \\ of people with psychological disorders may differ to their performance in the clinic or lab. It is important \\ that self-reports of minor cognitive issues are considered as both a potential risk and a maintaining factor \\ of illness. Substance use also needs to be considered in assessing cognitive failures.

\section{Disciplines \\ Education | Social and Behavioral Sciences}

\section{Publication Details} \\ Carrigan, N. \& Barkus, E. (2016). A systematic review of the relationship between psychological disorders \\ or substance use and self-reported cognitive failures. Cognitive Neuropsychiatry, 21 (6), 539-564.
}




\title{
A systematic review of the relationship between
}

\section{psychological disorders or substance use and self-reported} cognitive failures.

\author{
Nicole Carrigan ${ }^{\mathrm{a}, *} \&$ Emma Barkus ${ }^{\mathrm{a}}$ \\ ${ }^{a}$ School of Psychology, University of Wollongong, Wollongong, NSW, Australia. \\ *Correspondence: Nicole Carrigan
}

Phone: +61431392824

Fax: +61242214163

Email: nc957@uowmail.edu.au

Postal address:

Building 41

School of Psychology

Faculty of Social Sciences

University of Wollongong

Northfields Avenue

WOLLONGONG NSW 2522

AUSTRALIA

Emma Barkus

Phone: +61 242218134

Fax: +61242214163 
Email: ebarkus@uow.edu.au

Postal address:

Building 41

School of Psychology

Faculty of Social Sciences

University of Wollongong

Northfields Avenue

WOLLONGONG NSW 2522

AUSTRALIA

\section{Disclosure statement:}

Dr Emma Barkus is in receipt of a Young Investigator Award from the Brain and Behaviour Research Foundation (formally NARSAD), and also receives in kind support from GW Pharmaceuticals, UK. 


\begin{abstract}
:
Introduction: Cognitive failures are errors in normal everyday functioning. Individuals with psychological disorders may possess heightened vulnerability. We sought to review the literature on cognitive failures in psychological disorders to determine the nature of this association, and whether failures relate to neuropsychological performance. We also examine the relationship between cognitive failures and substance use since it is relevant to everyday cognition and cooccurs in many psychological disorders.
\end{abstract}

Methods: We conducted a systematic review of self-reported cognitive failures in psychological disorders and substance use, identifying 21 articles in total.

Results: Articles identified studied trauma, mood, and anxiety disorders, and schizophrenia. Substance use articles included nicotine, alcohol, cannabis, and ecstasy use. Cognitive failures were increased in some but not all papers; the most consistent findings were for depression, PTSD, and daily smokers of nicotine. Subjective failures did not correlate closely with neuropsychological outcomes in any disorders. We were unable to discern distinct profiles of failures for each disorder; rather they may reflect emotional dysregulation more broadly.

Conclusions: The real world cognitive experiences of people with psychological disorders may differ to their performance in the clinic or lab. It is important that selfreports of minor cognitive issues are considered as both a potential risk and a maintaining factor of illness. Substance use also needs to be considered in assessing cognitive failures.

Keywords: Cognitive failures; subjective cognition; psychological disorders; mental health; substance use. 
COGNITIVE FAILURES, PSYCHOLOGICAL DISORDERS, SUBSTANCE USE

\section{A systematic review of the relationship between psychological disorders or substance use and self-reported cognitive failures.}

\section{Introduction}

As people go about their daily lives, most experience the irritating phenomenon of cognitive failures - also known as cognitive slips or "brain farts." Common failures include finding yourself re-reading the same page of a book multiple times, or putting salt instead of sugar on your cereal. As these examples illustrate, cognitive failures occur during routine tasks that one would usually have no difficulty in successfully completing (Clark, Parakh, Smilek, \& Roy, 2011). As such, they represent a lapse in cognition in "real world" settings, rather than an ability deficit (Broadbent, Cooper, FitzGerald, \& Parkes, 1982).

Cognitive failures are experienced by everyone from time to time, and are normally distributed throughout the general population (Boomsma, 1998; Kanai, Dong, Bahrami, \& Rees, 2011). Some people are more prone to making errors than others; of interest are the factors that determine this vulnerability. Objective cognition largely captures (relatively) stable ability, whilst cognitive failures are thought to reflect capacity: where performance might shift depending on context (Carrigan \& Barkus, 2016). Cognitive failures are shaped by trait-based vulnerability factors related to personality (e.g. Bruce et al., 2007; Pfeifer, van Os, Hanssen, Delespaul, \& Krabbendam, 2009), but also appear to be shaped by fluctuating state factors including mood and stress (Ishigami \& Klein, 2009), wakefulness (Wallace, Vodanovich, \& Restino, 2003), and even time of day (Mecacci, Righi, \& Rocchetti, 2004).

In addition to these contributing factors, people suffering from psychological disorders are also thought to be more vulnerable to cognitive failures (Broadbent et al., 1982; Merckelbach, Muris, 
Nijman, \& de Jong, 1996). However, there has been an emphasis on traditional objective measures of cognition in both healthy and clinical populations, meaning knowledge around everyday cognitive functioning in psychological disorders is limited. This in turn places limitations on conceptualisation and treatment of patients' cognitive difficulties. For example, in schizophrenia, up to $27 \%$ of patients exhibit normal neuropsychological functioning on objective assessments (Palmer et al., 1997), despite severe impairment in daily life. If clinicians refer primarily to test performance, they are unlikely to comprehend the breadth of disruption to the real world functioning of their patients, and will thus be limited in their ability to provide effective treatment. There is therefore a need to improve our understanding of subjective experiences of cognition in patients' daily lives. This review will serve to form a preliminary picture of the association between cognitive failures and different psychological disorders.

\section{Measurement of cognitive failures}

There are a number of approaches utilised in measuring cognitive failures. Several experimental tasks have been designed to capture aspects of cognition essential to everyday life. For example, the Sustained Attention to Response Task (SART; Robertson, Manly, Andrade, Baddeley, \& Yiend, 1997) assesses susceptibility to everyday attention failures, whilst tip-of-the-tongue studies examine proneness to word retrieval failures (Maylor, 1990). Recently more naturalistic measures have been applied, such as testing prospective memory by instructing participants to call at a prescribed time in the future (Cuttler, Graf, Pawluski, \& Galea, 2011). Alongside such tasks, there has also been increasing interest in self-reported perceptions of everyday slips and failures; this will be the focus of the current article. Several self-report tools have been developed, with the most widely used being the Cognitive Failures Questionnaire (CFQ; Broadbent et al., 1982). The CFQ requires individuals to indicate how frequently they have 
COGNITIVE FAILURES, PSYCHOLOGICAL DISORDERS, SUBSTANCE USE

experienced a list of minor perceptual, memory, and action failures in everyday life; higher scores reflect a general vulnerability to slips. Interestingly, correlations with the CFQ have been used to confirm the ecological validity of objective measures of everyday cognition, including the SART (Smilek, Carriere, \& Cheyne, 2010a).

However, the use of self-reported cognitive failures leads to questions of validity. Given that neuropsychological assessments are considered the "gold-standard" method of capturing cognition, the poor correspondence between performance on neuropsychological assessments and self-reported slips is of concern to some authors (Donohoe et al., 2009; Wilhelm, Witthoeft, \& Schipolowski, 2010). It may be, however, that the two types of assessment are capturing different, but equally relevant and valid, aspects of cognition.

The reliability of self-reported cognitive failures is also questioned. Particularly pertinent is the association between cognitive failures and neuroticism (Broadbent et al., 1982; Gerald Matthews \& Wells, 1988). Two views of this relationship are expressed: neurotic people, 1) are genuinely more prone to everyday cognitive failures (Neupert, Mroczek, \& Spiro, 2008; Suls \& Martin, 2005), or 2) tend to exaggerate reports of failures due to their negative self-appraisal style (Wilhelm, Witthöft, \& Schipolowski, 2010). It is necessary to determine more imaginative methods for validating the assessment of cognitive failures to ensure that the concerns of critics can be addressed.

Certainly, the use of informants in cognitive failures could help to address concerns over both the validity and reliability of cognitive failures. Given the behavioural nature of many of the complaints captured under the banner of cognitive failures, it is possible that those living with one another could be aware of the extent to which they are experienced. Across the healthy 
COGNITIVE FAILURES, PSYCHOLOGICAL DISORDERS, SUBSTANCE USE

population, self-reported cognitive failures show moderate correlations with informant ratings (Broadbent et al., 1982; Mahoney, Dalby, \& King, 1998), as well as with real world outcomes such as the likelihood of being at-fault in a car accident (Larson \& Merritt, 1991). This suggests that self-reported cognitive failures are indeed of value as an indication of proneness to problems with real world cognition. Further studies are needed corresponding both subjective and informant ratings of cognitive failures to assist in addressing some of the measurement concerns; other creative methods such as real time assessment may also be of use.

\section{Cognitive failures in psychological disorders and substance use}

Feeling overwhelmed with the demands of life tends to go hand-in-hand with difficulty thinking clearly. Cognitive failures are known to be associated with stress (Mahoney et al., 1998) and negative affect (Payne \& Schnapp, 2014), and patients with a range of psychological disorders including depression, bipolar, generalised anxiety, and schizophrenia complain of similar difficulties (American Psychiatric Association, 2013). The link between these disorders and objective cognitive outcomes has been well covered (e.g. David, Zammit, Lewis, Dalman, \& Allebeck, 2008), however investigation of patients' experiences of everyday slips has been limited. There are two key possibilities for the nature of a relationship between psychopathology and cognitive failures: 1) problems with cognitive functioning in everyday life causally contribute to aspects of illness such as negative affect (e.g. Carriere, Cheyne, \& Smilek, 2008), or 2) vulnerable individuals' already compromised systems struggle to cope with daily stressors, resulting in cognitive failures (e.g.Matthews, Coyle, \& Craig, 1990). It is beyond the scope of this paper to elucidate how cognitive failures and psychological disorders influence each other; however, a review of the currently disparate literature will provide information about which particular disorders are most affected. 
COGNITIVE FAILURES, PSYCHOLOGICAL DISORDERS, SUBSTANCE USE

This review will also consider the effects of substance use on cognitive failures. This is of interest for a number of reasons. First, there is already a large body of research that has demonstrated the impact substance use has on everyday cognition. For example, ability to successfully carry out cognition necessary for safe driving is adversely impacted by use of substances including alcohol (Marczinski, Harrison, \& Fillmore, 2008) and cannabis (Downey et al., 2013). Whilst these findings are based on objective measures of cognition (i.e. driving simulators), they suggest that real world cognition - as in cognitive failures - may also be affected by substance use.

Second, there is an overlap between psychological disorders and substance use. A high proportion of individuals with a psychiatric diagnosis will either have co-morbid substance use disorders, or use substances including nicotine, alcohol, and illicit drugs (Weaver et al., 2003). In those studies that do measure cognitive failures in clinically-defined populations there tends to be a lack of consideration for the potential role of substance use, most likely due to the complexity of clinical presentations. Therefore it is important to consider any findings for the effects of substance use on cognitive failures, even those studies considering substance use in otherwise psychologically healthy individuals would provide useful information.

\section{Objectives of the current review}

There have been a number of studies examining cognitive failures in individuals with psychological disorders and in substance use, however their findings are yet to be drawn together. This review will seek to determine whether or not there is a relationship between cognitive failures and different psychological disorders or substance use, and how this relates to objective cognitive outcomes. Specifically, three core questions will be explored: 
1) What is the relationship between cognitive failures and psychological disorders?

2) What is the relationship between cognitive failures and substance use?

3) How do subjective cognitive failures relate to performance on objective tasks in people with psychological disorders or in substance users? 


\section{Method}

We designed and reported this systematic review based on the PRISMA (Preferred Reporting Items for Systematic reviews and Meta-Analyses) statement, an internationally recognised 27item method ensuring the highest standard in systematic reviewing (Liberati et al., 2009). PRISMA was developed as an update to previous standards provided by the QUOROM (Quality Of Reporting Of Meta-analyses) statement, and is based on the definitions of systematic reviews and meta-analyses set forth by the Cochrane Collaboration.

\section{Search strategy}

Studies were identified by searching electronic databases and scanning reference lists. PsycINFO (1967-March 2016), Web of Science’s Social Sciences Citation Index (1956-March 2016), Scopus (1960- March 2016) and the Cochrane database were searched using the following index items via Boolean search criteria: "cognitive failure* OR cognitive slip* OR subjective cogniti* AND everyday;" "cognitive slip* OR cognitive failure* OR subjective cogniti* AND daily." These search terms were derived from examination of seminal cognitive failure articles (e.g. Broadbent et al., 1982; Wallace, Kass, \& Stanny, 2002). Several other search terms were considered but ultimately excluded.

Whilst "mind-wandering" is sometimes used interchangeably with cognitive failures, it refers to a phenomenon that may result in failures in thought or action, rather than errors themselves. In addition, preliminary searches found that the majority of recent papers focus on mindfulness or the content of daydreams, rather than errors that may arise. "Accident-proneness" is another term that has previously been associated with cognitive failures (e.g. Reason, 1979), however this is now largely confined to human factors research where it refers to a concept encapsulating 
COGNITIVE FAILURES, PSYCHOLOGICAL DISORDERS, SUBSTANCE USE

issues beyond human errors in cognition. The chosen search terms therefore reflect the current review's focus on cognitive failures, defined as cognitive capacity in everyday life which is fluid and may fluctuate according to shifts in factors such as illness and environment (Carrigan \& Barkus, 2016).

No limits were applied for year of publication or language, and translated foreign papers were accessed. Reference lists of key articles were hand-searched. All types of studies apart from case studies and theoretical papers were included in the search. The last search was run on $15^{\text {th }}$ March, 2016.

\section{Eligibility criteria}

Inclusion and exclusion criteria were postulated prior to the search. Studies were included if they were:

- Published in a refereed journal;

- Identified cognitive failures or subjective cognitive complaints as one of their primary measures or outcomes;

- Sampled from populations with any psychological disorder listed in the Diagnostic and Statistical Manual, including substance use disorders; OR

- Sampled from healthy populations but examined substance use including that of alcohol and other drugs, but excluding caffeine; and

- Utilised the CFQ as a subjective measure of everyday cognitive performance.

Studies were excluded if they: 
- Sampled from a non-psychologically disordered population, including those with neurological disorders such as dementia or traumatic brain injury, or those with other cognitive disorders such as dyslexia;

- Were attempts to validate the CFQ with specific populations (e.g. cultural, language groups) or created for specific populations (e.g. elderly people);

- Came from non-psychological or health-related research fields (e.g. ergonomics); or

- Studied outcomes of a new intervention.

This search strategy focused on the CFQ, excluding objective, laboratory-based measures such as the SART. This enabled an exploration of everyday cognitive functioning, with self-reported failures capturing real world errors that cannot be replicated in the lab. It should also be noted that there are a number of other self-report tools available including the Attention-Related Cognitive Errors Scale (ARCES; Smilek, Carriere, \& Cheyne, 2010b), Short Inventory of Minor Lapses (SIML; Reason, 1993), and the Prospective and Retrospective Memory Failures Questionnaire (PRMQ; Smith, Della Sala, Logie, \& Maylor, 2000). However, preliminary searches failed to identify a substantial number of articles that utilised these measures with clinical populations. In addition, the $\mathrm{CFQ}$ is one of the broadest measures, covering slips in memory, attention, and perception. Therefore, a sole focus on the CFQ was chosen to ensure consistency and clarity.

This review was left open to clinical populations with any kind of psychological disorder as listed in the DSM 5, excluding those defined by neurological issues or severe cognitive impairment, such as dementia, learning disorders, and ADHD. Given the field of cognitive failures is still relatively small, this relatively open search approach was taken as a means of providing a preliminary overview of the literature, as per the aims of this review. 
COGNITIVE FAILURES, PSYCHOLOGICAL DISORDERS, SUBSTANCE USE

Case studies, letters to the editor, and conference abstracts were excluded. The researchers screened titles and abstracts of the articles gathered during the search against the exclusion criteria. Selected articles were then read and excluded if they did not meet criteria.

INSERT FIGURE 1 ABOUT HERE 


\section{Results}

We included 21 articles in the review. The studies varied widely in their research design and grouping of participants. Almost all of the studies used correlational designs $(n=19)$, with some longitudinal studies $(n=2$; Manning, Teo, Guo, Wong, \& Li, 2016; van den Bosch, Rombouts, \& van Asma, 1993).

\section{Study characteristics}

\section{Location}

The largest portion of articles came from the United Kingdom $(n=8)$, these were largely studies looking at substance use. The United States contributed the next largest portion $(n=4)$, followed by the Netherlands $(n=3)$, and Australia $(n=1)$, Bosnia-and-Herzegovina $(n=1)$ Canada $(n=$ 1), the Czech Republic $(n=1)$, Ireland $(n=1)$, and Singapore $(n=1)$.

\section{Study populations}

We identified studies focusing on a range of different psychological disorders. Sampled populations included those with:

- Affective disorders, including major depressive and bipolar disorders.

- Anxiety disorders.

- Post-traumatic stress disorder.

- Schizophrenia.

We identified papers sampling from users of the following substances:

- Nicotine. 
- Alcohol.

- Cannabis, ecstasy, and polydrug use.

We examined the studies and arranged them into sub-tables according to the disorder or substance they examined. Some articles contained overlapping topics; these were placed into sub-tables based on their primary focus.

Whilst it was not the purpose of this paper to additionally conduct a meta-analysis, we calculated effect sizes for each study that provided sufficient statistical detail. The majority of studies identified for this review provided CFQ means and standard deviations, which enabled calculation of standardised mean differences (Lipsey \& Wilson, 2001). As such, $d$ and 95\% confidence intervals were calculated for those studies that presented data on between-groups differences in CFQ scores, and are presented in Tables 1,2, and 3. A small number of studies instead reported correlations between CFQ scores and those of diagnostic measures; in these cases $r$ correlation coefficients were transformed into $d$ for ease of comparison (Borenstein, Hedges, Higgins, \& Rothstein, 2009). The size of these effects as per Cohen's (1988) suggested classifications are also indicated in the tables.

\section{Relationship between psychological disorders and cognitive failures}

\section{Affective disorders}

As per Table 1, four papers examined depression and consistently demonstrated a profile of elevated cognitive failures (Farrin, Hull, Unwin, \& Wykes, 2003; MacQueen, Galway, Hay, Young, \& Joffe, 2002; Preiss, Kramska, Dockalova, Holubova, \& Kucerova, 2010; Sullivan \& Payne, 2007). Effect sizes for the differences between depressed and control individuals were 
COGNITIVE FAILURES, PSYCHOLOGICAL DISORDERS, SUBSTANCE USE

generally large. In bipolar populations there were only two studies identified, neither of which found any evidence of a relationship between the disorder and heightened cognitive failures.

\section{INSERT TABLE 1 ABOUT HERE.}

These studies mirror recent attempts to uncover a neuropsychological profile of depression. These have so far identified central deficits in the objectively-measured domains of attention, executive functioning, and to a lesser extent episodic memory (e.g. McDermott \& Ebmeier, 2009; Rock, Roiser, Riedel, \& Blackwell, 2014).

The presence of objective deficits in patients in remission supports cognitive impairment as a core feature of depression, impacting psychosocial functioning independent of mood fluctuations. Accordingly, patients whose mood responds positively to antidepressant treatment continue to report heightened cognitive failures in everyday life (MacQueen et al., 2002). Farrin et al. (2003) described a vicious cycle between depression and cognitive failures, whereby normal errors trigger strong, negative reactions (thoughts, feelings) that drain cognitive resources, further increasing the chance of errors. Similar levels of failures were noted in those with seasonal affective disorder (Sullivan \& Payne, 2007), suggesting that the failures may not be specifically associated with any one subtype of depression.

However, two studies of individuals with bipolar disorder found that patients in various phases of illness (depressed, hypomanic and euthymic) tended to report fewer failures relative to both healthy controls (Schouws, Comijs, Stek, \& Beekman, 2012) and their own objectively-assessed neuropsychological deficits (Burdick, Endick, \& Goldberg, 2005). This pattern of "underreporting" is difficult to interpret, as illness chronicity is linked to significant confounds such as mood stabilising medications and the adjustment or lowering of perceptions/expectations of 
COGNITIVE FAILURES, PSYCHOLOGICAL DISORDERS, SUBSTANCE USE

functioning over time. In addition, hypomanic symptoms may reduce awareness of errors made in an everyday context.

\section{Non-affective disorders}

We identified only seven articles that focused on psychological disorders other than mood disorders (Table 2). These included two examining anxiety disorders, three on trauma-related disorders, and two on schizophrenia. The findings of these papers were less consistent than those regarding depression. There appear to be weak links between increased cognitive failures and anxiety (Grisham, Norberg, Williams, Certoma, \& Kadib, 2010; Merckelbach et al., 1996), and one of these papers found a comparatively stronger association with depression (Merckelbach et al., 1996). The findings regarding schizophrenia were mixed, with one group identifying no increase in failures for psychosis compared to controls (Donohoe et al., 2009), whilst the other found a large difference, comparable to the heightened reports of those with major depression (van den Bosch et al., 1993). The most robust findings related to trauma, with CFQ scores being greatly increased in those with PTSD symptoms (Boals \& Banks, 2012; Boals, 2008; Koso, Sarač-Hadzihalilovic, \& Hansen, 2012). More detailed information about these findings is provided following Table 2 .

INSERT TABLE 2 ABOUT HERE.

\section{Anxiety disorders}

Anxiety symptoms in a healthy student population were correlated positively with CFQ scores (Merckelbach et al., 1996). However, in another sub-study the same authors found that clinically anxious patients reported failures similar to controls, and less than depressed patients (Merckelbach et al., 1996). Conversely, clinically anxious participants in the second identified 
COGNITIVE FAILURES, PSYCHOLOGICAL DISORDERS, SUBSTANCE USE

anxiety article reported significantly more errors than controls, although there were no differences between hoarding and non-hoarding patients (Grisham et al., 2010). It was somewhat surprising that there were so few papers on failures and anxiety disorders, given the significant impact anxiety can have on everyday functioning. There were also some limitations of the identified papers; primarily, both of these studies featured a mixed sample rather than being disorder-specific. Included were individuals with a range of anxiety disorders, such as panic disorder, social phobia, and OCD, as well as those with co-morbid depression. Given the heterogeneity of these disorders, the current review provides only a limited glimpse of the potential link between anxiety and everyday cognition.

\section{Post-traumatic stress disorder}

Individuals with post-traumatic stress disorder (PTSD) are another group experiencing a high frequency of cognitive failures (Boals \& Banks, 2012; Boals, 2008), with symptom severity related to both daily slips and neuropsychological deficits (Koso et al., 2012). Intrusive memories surrounding trauma and "flashbacks" are thought to drain cognitive resources, increasing the likelihood of slips (Boals, 2008). Importantly, situational stress appears to interact with PTSD symptoms for an additive effect that can trigger even more failures (Boals \& Banks, 2012).

Whilst the findings in these three articles were consistent, it is notable that they involved quite different forms of PTSD. Boals and Banks' study (2012) utilised a student population reporting the experience of at least one traumatic lifetime event which led to clinical symptoms of PTSD. Such events included a serious accident, or an unexpected death. The other studies, meanwhile, included survivors of Holocaust concentration camps (Boals, 2008) and servicemen who were 
COGNITIVE FAILURES, PSYCHOLOGICAL DISORDERS, SUBSTANCE USE

torture survivors from the Bosnian war (Koso et al., 2012). These prolonged experiences of pain and harm would precipitate complex trauma, quite distinct to the one-off incidents faced by students. Whilst the "brain-drain" caused by intrusive memories provides one explanation of cognitive failures, complex trauma involves sequelae additional to PTSD, such as elevated arousal systems, somatisation, dissociation, and high risk for repeated harm (Herman, 1992); all of which may also impact cognition. Other factors of potential significance that have yet to be considered are time since traumatic event (e.g. 20 years between Bosnian war and article publication vs. 60 years between Holocaust and article publication), and presence of psychotic symptoms.

\section{Schizophrenia}

Schizophrenia was another disorder for which no distinct profile of cognitive failures is yet evident, with findings of both increased (van den Bosch et al., 1993) and normal levels (Donohoe et al., 2009) of everyday problems.

These studies included two quite different groups: recently hospitalised patients versus "stable" chronic patients. A possible explanation for the discrepancy in findings, therefore, is difference in phase of illness. Chronic sufferers may develop compensatory strategies through their experiences, and thus evidence fewer cognitive failures than younger individuals recovering from their first psychotic episode. However, given the paucity of information on inclusion criteria and sample characteristics in the current literature, further phase-specific research is necessary before such conclusions can be drawn.

Broadly, positive psychotic symptoms were associated with failures whilst negative symptoms were not (van den Bosch et al., 1993). Van den Bosch et al. (1993) suggest the complexity of 
sensory information in everyday life overloads compromised sensory processing in psychosis. This problem is avoided by those whose prominent symptoms are negative, which often includes avoidance of external stimuli through social withdrawal. However, this finding is in contradiction to research on objective cognition, where the severity of negative rather than positive symptoms is more closely associated with cognitive impairment (Addington, Addington, \& Maticka-Tyndale, 1991). Further research examining the mechanisms underpinning the relationship between cognitive failures and schizophrenia may highlight a significance of interactions between symptoms and day-to-day factors, such as stress and time of day.

\section{Relationship between substance use and cognitive failures}

Eight articles explored the impact of substance use on cognitive failures: two on nicotine, one on alcohol, and five on cannabis, ecstasy, or polydrug use (Table 3). Of these, only the alcohol paper studied a clinical population: patients with alcohol dependence disorder. Daily smoking seemed to be associated with increased failures (Parrott \& Kaye, 1999; Wan, Friedman, Boutros, \& Crawford, 2008), as did alcohol dependence (Manning et al., 2016). The literature on cannabis and ecstasy did not provide clear evidence; only cannabis seemed to have a small detrimental effect on everyday cognition (Fisk \& Montgomery, 2008).

\section{INSERT TABLE 3 ABOUT HERE.}

Interestingly, none of these articles examined acute intoxication, focusing instead on functioning during withdrawal and periods of abstinence/sobriety, and incorporating a mixture of occasional and chronic users. It must be noted that few of these studies controlled for time since last use, with most asking for a specific period of abstinence (e.g. 7 days since last ecstasy use) and relying on self-report only, rather than any objective measures of compliance. Given the 
COGNITIVE FAILURES, PSYCHOLOGICAL DISORDERS, SUBSTANCE USE

possibility of intraindividual variations in drug clearance rates (as in ecstasy; e.g. De La Torre et al., 2000), the findings presented in this review should be viewed as providing only an early indication of the patterns of real life cognition associated with substance use.

\section{Nicotine}

There has been much research conducted into the effects of nicotine on cognition, with immediate beneficial effects after use evident even in non-users (Heishman, Kleykamp, \& Singleton, 2010). However, this review identified only two papers that looked at the subjective experience of cognitive functioning in smokers. Daily smokers report more failures than those who smoke occasionally (Wan et al., 2008), and specifically, smokers experience more slips during periods of abstinence (Parrott \& Kaye, 1999). Abstaining smokers also reported more stress, lower mood, and reduced arousal, and experienced everyday life as having more hassles; this highlights the significance of nicotine for sustaining normal functioning in users (Parrott \& Kaye, 1999). This paper also highlights the complexity concerning the nature of the relationship between cognitive failures and substance use. Potentially there are other mediating or exclusively contributing factors such as mood and anxiety which could fully or partially account for cognitive failures' association with substance use. These need to be taken alongside any alterations in brain functioning which may be a direct results of the substance use; although it is presumed in non-clinical samples that this would lead to elevated cognitive failures being transitory and temporally related to substance use. In assessing the existing research, it is important to note that both studies utilised groups with large variations in the number of cigarettes smoked daily (e.g. range from 5-60 daily for abstaining smokers; Parrot \& Kaye, 1999). Given the well-documented effects of nicotine withdrawal, such large differences in dosage would be expected to impact upon cognition to different degrees. 
COGNITIVE FAILURES, PSYCHOLOGICAL DISORDERS, SUBSTANCE USE

Nevertheless, an important issue raised in these two articles is the potential role of nicotine as a kind of self-regulator, important for sustaining normal functioning and without which, cognition may be impaired. Related to this, Wan et al. (2008) noted potential patterns of use of nicotine for self-medication in schizotypal individuals, a group known to have increased emotional reactivity (Collip et al., 2013). Alongside aiding cognition, therefore, nicotine may also play an essential role in assisting emotion regulation in a subgroup of users, with use having an indirect impact on cognitive failures.

\section{Alcohol}

The only article focusing on alcohol use was also the only one to study a population with a substance use disorder (Manning et al., 2016). Individuals with alcohol dependence complain of increased cognitive failures even after a period of detoxification. At three months follow up, abstainers reported significant reductions in cognitive failures, whilst those who relapsed did not. This would suggest that, at least for alcohol dependence, cognitive failures is related to the intoxication and withdrawal associated with the substance use itself, rather than being related to any longer lasting changes in brain structure or functioning. Implicit within this is that cognitive failures result from alcohol dependence and are not a potential risk marker for it.

The lack of articles studying alcohol was surprising, given the extensive literature on the effects of alcohol intoxication on cognition including executive function, inhibitory control, memory, and motor control (Peterson, Rothfleisch, Zelazo, \& Pihl, 1990; Schweizer et al., 2006). There have also been more recent attempts to explore the impact of alcohol on cognition in more naturalistic settings (e.g. bars; Lyvers \& Tobias-Webb, 2010), however the lack of studies of subjective perceptions of cognition is stark when compared to research around other substances. 
COGNITIVE FAILURES, PSYCHOLOGICAL DISORDERS, SUBSTANCE USE

\section{Cannabis, ecstasy and polydrug use}

Five papers examined cannabis or ecstasy use; these proved difficult to isolate in users (Montgomery \& Fisk, 2007), and many researchers chose to include polydrug users. Unsurprisingly, given the contrasting psychopharmacological effects of depressants and stimulants, findings were mixed. A small sample of both ecstasy and cannabis users recruited by Rodgers (2000) did not report any subjective impairment, but cannabis was associated with heightened failures in another (Fisk \& Montgomery, 2008). Cannabis users' complaints about problems with daily functioning were affirmed by their significant others, despite an absence of demonstrable neuropsychological deficits (Fisk \& Montgomery, 2008), adding weight to the notion that neuropsychological assessments are not necessarily capturing all the information related to real world cognitive functioning.

Chronic ecstasy users reported problems with memory specifically but did not endorse cognitive failures in general (Heffernan et al., 2001). One study utilising highly chronic ecstasy users (average 346.5 tablets in lifetime prior to study) did find high levels of cognitive failures, but also acknowledged that most heavy ecstasy users are polydrug users (Montgomery \& Fisk, 2007). Specifically, many people use cannabis to manage the low mood and irritability associated with the "come down" from ecstasy (Klugman \& Gruzelier, 2003); typically this pattern of use would be most common in chronic consumers. Indeed, further analyses in the study of chronic ecstasy users suggested cannabis as the key predictor of failures (Montgomery \& Fisk, 2007). These findings reflect the literature around objective measures of cognitive functioning, where there are also conflicting findings as to whether ecstasy or cannabis is actually the main source of impairment (e.g. Croft, Mackay, Mills, \& Gruzelier, 2001; Klugman \& Gruzelier, 2003). In addition, there is the possibility that the combined effects of ecstasy and 
COGNITIVE FAILURES, PSYCHOLOGICAL DISORDERS, SUBSTANCE USE

cannabis produce a cascade of neurobiological events which are particularly toxic. Further work is needed to tease apart the interacting effects of substances, indeed, the effects of legal substances such as alcohol and nicotine are often forgotten about in studies concerning illicit substances.

The role of self-awareness in reporting cognitive failures was raised quite frequently in the substance use literature. It was proposed that metacognitive deficits resulting from chronic use of illicit substances may prevent accurate reflection on everyday performance (Rodgers, 2000). However, informant-self correlations support that cannabis users are capable of reporting on difficulties; the lack of association with objective cognitive outcomes suggests that the subtlety of users' real life cognitive problems are not detectable in the isolation and calm of lab testing (Fisk \& Montgomery, 2008).

\section{Subjective cognitive failures versus performance on objective tasks in individuals with psychological disorders}

Several papers compared cognitive failures and objectively assessed cognitive performance in a range of psychological disorders and patterns of substance use $(n=14)$. A range of objective domains were tested for correlation with everyday cognition; with attention, executive function and memory being predominant. In line with our previous review on the link between subjective and objective cognition in healthy populations (Carrigan \& Barkus, 2016), there were no consistent associations evident between cognitive failures and any objective domains of cognition. These findings are displayed in Table 4, which displays the domains examined and whether a relationship with cognitive failures was found.

INSERT TABLE 4 ABOUT HERE 
COGNITIVE FAILURES, PSYCHOLOGICAL DISORDERS, SUBSTANCE USE

\section{Psychological disorders}

There was a consistent disparity between neuropsychological outcomes and self-reports of daily functioning of people with a diagnosed psychological disorder, as in healthy populations (Carrigan \& Barkus, 2016). Farrin et al. (2003) found a relationship between CFQ scores and errors and longer reaction times in depression, however other studies of affective disorders failed to uncover any relationship (Burdick et al., 2005; Preiss et al., 2010; Schouws et al., 2012). Cognitive biases present in individuals with mood disorders could be argued to skew reporting in a negative direction, however the experience of poor concentration is a well-accepted symptom of depression (American Psychiatric Association, 2013; Watts \& Sharrock, 1985). This disparity may actually be due to problems with the ecological validity of current objective measures.

An article studying war veterans with PTSD was the only study to identify objective test parity with cognitive failures across all domains tested, including executive function, memory and verbal function (Koso et al., 2012). This perhaps supports the proposed mechanism behind increased failures in PTSD, whereby intrusive memories increase slips via depletion of cognitive resources (Boals, 2008). These findings also highlight the significance of the link between PTSD symptoms (such as flashbacks) that are precipitated by "triggers" in daily life, and the level of disruption to cognitive, occupational, and social function experienced by sufferers. Further consideration of the role of situational factors in cognitive failures in psychopathology more generally may serve to increase our understanding of this phenomenon.

Some final findings of note were produced by Donohoe et al. (2009) in their study on schizophrenia. The authors suggested that one element of insight into illness is cognitive insight or awareness of cognitive functioning. They suggested that the CFQ essentially provides a 
COGNITIVE FAILURES, PSYCHOLOGICAL DISORDERS, SUBSTANCE USE

measure of cognitive insight, and so its utility lies only in identifying discrepancies between neuropsychological performance and self-reported perceptions of the same. Predicted premorbid IQ (as per the Wechsler Test of Adult Reading) and episodic memory were both correlated with CFQ scores only for a few patients with intact clinical (i.e. illness) insight. That is, clinical insight was necessary, but not sufficient, for cognitive insight.

\section{Substance use}

There was an even greater "gap" between objective and subjective cognition in substance use. As mentioned earlier, this was proposed to be due to metacognitive deficits in drug users (Rodgers, 2000), whether due to substance use or personality factors that predispose to substance use.

Whilst correlations between subjective and objective cognition were not explored, ecstasypolydrug users had both higher CFQ ratings and poorer working memory performance than nonusers (Montgomery \& Fisk, 2007), and alcohol dependent patients had increased CFQ scores as well as memory, working memory, and executive function issues (Manning et al., 2016). More significant cognitive problems may be expected in the clinical population of the latter study, but the former focused on highly chronic ecstasy users, albeit without a diagnosed disorder. Perhaps individuals only experience a noticeable severity of problems and/or unable to compensate for them once a certain threshold of substance abuse is surpassed. 


\section{Discussion}

This review identified a range of studies on cognitive failures in different psychological disorders. Failures in substance users were also explored, given that substance use is known to influence objective cognitive performance, as well as being closely related to psychological disorders.

\section{What is the relationship between cognitive failures and psychological disorders?}

There appears to be a link between a number of psychological disorders and heightened reports of cognitive failures. Patients with depression and PTSD were consistently more prone to everyday failures than controls, with medium to large effect sizes. Researchers in both of these disorders posited that particular aspects of their psychopathology drain cognitive resources to result in failures: in depression, catastrophic reactions to perceived errors (Farrin et al., 2003); in PTSD, intrusive thoughts and flashbacks (Boals, 2008). Individuals with bipolar disorder were the only group to report fewer cognitive failures than controls, which raised the issue of insight; this will be discussed in detail later.

It is important to note that the existing research is largely correlational in nature. Therefore, it is still unclear whether cognitive failures are consequent of other psychological symptoms or part of the core symptoms present in these disorders. Consideration also needs to be given as to whether cognitive failures are part of the inherited vulnerability for psychological disorders. However, given the lack of disorder specificity, as well as cognitive failures' correlation with neuroticism in both healthy and disordered populations (van den Bosch et al., 1993; Wilhelm, Witthöft, \& Schipolowski, 2010), it is possible that cognitive failures could relate to psychological distress or problems of emotion regulation more generally. 


\section{What is the relationship between cognitive failures and substance use?}

The picture of cognitive failures in substance use is even less clear. Nicotine seems to be associated with cognitive failures in a dose-response fashion according to level of use, with daily smokers experiencing more failures than non-daily smokers (Wan et al., 2008). However, the significant factor appears to be withdrawal rather than intoxication, with abstaining smokers suffering more daily hassles and failures than non-abstainers (Parrott \& Kaye, 1999). Nicotine is often used as an emotion regulation tool (Schleicher, Harris, Catley, \& Nazir, 2010) with deprivation reducing thresholds for coping with stress. In abstaining smokers, increased failures may therefore occur alongside or as a kind of cognitive consequence of stress.

Surprisingly, there was only one article identified that considered alcohol use; this focused on a clinically dependent population and found CFQ scores were still heightened immediately postdetox, but were reduced after three months in those who continued to abstain (Manning et al., 2016). Patients who relapsed did not experience the same reduction in cognitive failures, suggesting that time since alcohol dependence is perhaps more important than brain changes associated with abuse for everyday cognitive functioning. To highlight the limited research on self-reported everyday cognition and alcohol, we excluded only one alcohol article on the basis that it utilised a different measure of subjectively-perceived cognition (Ling et al., 2003). This paper found that level of alcohol consumption in a non-clinical sample correlated with level of everyday memory problems, with heavy drinkers reporting more issues than moderate drinkers, and moderate drinkers more than abstainers. These papers suggest, similarly to nicotine, that potentially it may be the withdrawal state which is potent to predisposing to cognitive failures. 
COGNITIVE FAILURES, PSYCHOLOGICAL DISORDERS, SUBSTANCE USE

Long term heavy cannabis use appears to be linked to increased vulnerability to failures to a greater extent than ecstasy (Fisk \& Montgomery, 2008; Montgomery \& Fisk, 2007). Findings were overall limited, inconsistent, and complicated by polydrug use.

Existing papers, whilst limited, suggest substance use has the potential to increase cognitive failures. As such, substance use needs further consideration as an issue affecting measurement in further research into everyday cognition in clinical and non-clinical populations.

\section{How do subjective cognitive failures relate to performance on objective tasks in people with psychological disorders or in substance users?}

There was no evidence of a definitive link between objective neuropsychological outcomes and self-reported cognitive failures in either psychological disorders or substance use. Comparison between these two approaches to measuring cognition represents a key topic of interest, and contributes to the ongoing debate regarding self-awareness, reliability, and validity of subjective reports of cognition. Some authors suggest reported failures in the absence of neuropsychological deficits were an indication of impaired self-awareness related to illness (as in schizophrenia; e.g. Donohoe et al., 2009). This mirrors the debate around neuroticism, where increased self-reported failures are viewed as reflecting tendency for negative self-evaluation. Poor self-awareness is not necessarily indicated by a lack of relationship between objective and subjective cognitive measures. Rather, everyday cognitive failures may tap into aspects of cognition quite different to those accessed in the lab. If affective dysregulation is indeed a significant contributor to vulnerability for cognitive failures, then real world stressors both external and internal are likely to trigger errors for psychologically vulnerable individuals. This would occur regardless of one's level of objective neuropsychological ability, hence the low 
COGNITIVE FAILURES, PSYCHOLOGICAL DISORDERS, SUBSTANCE USE

correlation between lab-based and real world performance. The current findings highlight the need to develop more ecologically valid measures of cognition, particularly ones that can capture real world emotional factors more readily.

\section{Limitations}

An earlier goal of this review was to elucidate distinct profiles of real life cognitive functioning for specific psychological disorders. However, the literature search revealed that this would not be possible. The number of studies for each disorder was limited; some disorders were the focus in as few as one or two articles, and others were not studied at all. The lack of studies was surprising, given the wide acceptance as "common knowledge" (as well as being acknowledged in the DSM 5) that mild cognitive issues often go hand-in-hand with psychological disorders. Similarly, we were able to identify only a handful of articles exploring the link between CFQ scores and substance use. Most notably missing were papers regarding alcohol use, given its global popularity and legality.

Ideally, a PRISMA review would also include an analysis of the quality of articles. However, this was not possible. This area of research is relatively small, and the necessarily broad scope of the search meant that articles were primarily correlational, using a variety of populations and methods; this makes comparisons using one set of criteria difficult. In addition, there remain inconsistencies in how cognitive failures are conceptualised. As such, it is important to qualify conclusions of the current review as tentative and preliminary.

There are a few broad limitations identified which form recommendations for future research. In particular, phase of illness for clinical populations was not always considered. Both cognitive functioning and perceptions of functioning may shift over time. For example, individuals in 
COGNITIVE FAILURES, PSYCHOLOGICAL DISORDERS, SUBSTANCE USE

prodromal stages of illness are likely to report increased cognitive problems (e.g. as in psychosis;

Schultze-Lutter, Klosterkötter, \& Ruhrmann, 2014), which may reflect acute awareness of decline in their functioning. The sense of there being "something wrong" may in itself ensure subjective monitoring is heightened. Chronic sufferers, by contrast, may have a different profile of failures; perhaps due to improvements in cognition related to medication, stabilisation of symptoms, development of compensatory strategies, or the lowering of expectations of their own capacities. Additionally, further studies into clinical populations would benefit from consideration of substance use, and attendance to the pharmacodynamics of the substances concerned.

\section{Clinical implications}

Despite the limitations of this review, the current findings highlight important implications for clinical practice. First, previous findings in healthy populations that negative affect and psychological distress increase cognitive failures can now be extended. Psychological distress seems to impact day-to-day cognitive functioning proportionately, such that individuals at the extremes of the distress continuum, (i.e. those with clinical disorders) report significantly higher levels of failures than those with subclinical levels of distress. Currently, the extent to which subtle cognitive deficits are considered by clinicians is limited (Burdick et al., 2005). A brief, self-report tool such as the CFQ could be introduced at the assessment stage in addition to neuropsychological measures in order to better inform clinicians of the particular struggles faced by patients. Similarly, cognitive failures could be used to monitor shifts in perceived daily functioning during treatment. Cognitive behavioural therapies could be designed to address cognitive failures directly; normalising the experience of mistakes, helping clients to identify and mediate the effects of triggers for slips and failures such as stress. 


\section{Conclusions and future directions}

It has previously been suggested that cognitive failures reflect both trait vulnerabilities and the influence of fluctuating state factors (Carrigan \& Barkus, 2016). We can now add to this that a range of psychological disorders including depression, anxiety, PTSD, and schizophrenia are all associated with increased self-reported failures in everyday life. In addition, use or withdrawal from substances including nicotine, alcohol, and cannabis may also lead to heightened failures, particularly in those whose pattern of use is chronic. Self-reported cognitive failures do not correlate with objective measures of cognition in either clinical or substance use populations, suggesting they may measure unique aspects of cognition.

The next step in this area of research will be to determine whether some common factor is responsible for heightened cognitive failures across both clinical and non-clinical individuals. For example, we already know that cognitive failures are associated with negative affect and neuroticism in healthy populations; one possibility is that emotional dysregulation increases vulnerability to slips. Another important aspect of further research into cognitive failures will be attempts to resolve the ongoing debate around the validity of self-reports, specifically with regards to the role of personality traits that may impact the accuracy of self-perceptions, such as neuroticism.

Although this review has focused on simple, retrospective self-reports, there are some new approaches to measurement of subjectively-perceived cognitive failures which will likely be of value in answering some of these remaining questions. A methodology of particular interest is ambulatory assessment, also known as experience sampling (e.g. Myin-Germeys, Delespaul, \& van Os, 2003). This involves capturing self-reports of errors in vivo; failures are reported as they 
occur during everyday activities, removing memory bias. Another major benefit of the use of experience sampling is the possibility for studying changes in functioning at multiple time points throughout each day. This would allow for examination of fluctuations, and the factors which may interact with trait and illness-related vulnerability to shape these shifts, such as time of day, stressors, and substance use. To date, only a handful of studies have utilised experience sampling to study cognitive failures in healthy populations (Kane et al., 2007; Lange \& Süß, 2014; McVay, Kane, \& Kwapil, 2009; Neupert et al., 2008). This approach would seem to be the next step towards studying real world cognitive capacity in an ecologically valid way, but as it is not yet widespread, retrospective self-reports as captured via measures such as the CFQ remain invaluable in providing a picture of cognition as it translates into everyday life. 


\section{References}

Addington, J., Addington, D., \& Maticka-Tyndale, E. (1991). Cognitive functioning and positive and negative symptoms in schizophrenia. Schizophrenia Research, 5(2), 123-134. doi:10.1016/0920-9964(91)90039-T

American Psychiatric Association. (2013). Diagnostic and statistical manual of mental disorders (5th ed.). Arlington, Va.: American Psychiatric Association.

Boals, A. (2008). Intrusive thoughts and everyday cognitive failures in Holocaust survivors. Stress and Health, 24(5), 401-405. doi:10.1002/smi.1191

Boals, A., \& Banks, J. B. (2012). Effects of traumatic stress and perceived stress on everyday cognitive functioning. Cognition \& Emotion, 26(7), 1335-43. doi:10.1080/02699931.2011.651100

Boomsma, D. I. (1998). Genetic analysis of cognitive failures (CFQ): a study of Dutch adolescent twins and their parents. European Journal of Personality, 12(5), 321-330. doi:10.1002/(SICI)1099-0984(1998090)12:5<321::AID-PER334>3.0.CO;2-5

Borenstein, M., Hedges, L. V., Higgins, J. P. T., \& Rothstein, H. R. (2009). Introduction to Meta-Analysis (p. 452). Chichester, UK: John Wiley \& Sons, Ltd.

Broadbent, D. E., Cooper, P. F., FitzGerald, P., \& Parkes, K. R. (1982). The Cognitive Failures Questionnaire (CFQ) and its correlates. British Journal of Clinical Psychology, 21(1), 1-16. doi:10.1111/j.2044-8260.1982.tb01421.x

Bruce, Amanda, S., Ray, William, J., Carlson, \& Richard, A. (2007). Understanding cognitive failures: what's dissociation got to do with it? Am. J. Psychol., 120(4), 553-563. doi: $10.2307 / 20445425$

Burdick, K. E., Endick, C. J., \& Goldberg, J. F. (2005). Assessing cognitive deficits in bipolar disorder: are self-reports valid? Psychiatry Research, 136(1), 43-50. doi:10.1016/j.psychres.2004.12.009

Carriere, J. S. A., Cheyne, J. A., \& Smilek, D. (2008). Everyday attention lapses and memory failures: the affective consequences of mindlessness. Consciousness and Cognition, 17(3), 835-47. doi:10.1016/j.concog.2007.04.008

Carrigan, N., \& Barkus, E. (2016). A systematic review of cognitive failures in daily life: Healthy populations. Neuroscience and Biobehavioral Reviews, 63, $29-42$. doi:10.1016/j.neubiorev.2016.01.010 
Clark, A. J., Parakh, R., Smilek, D., \& Roy, E. A. (2011). The Slip Induction Task: Creating a window into cognitive control failures. Behavior Research Methods, 44(2), 558-74. doi:10.3758/s13428-011-0154-0

Cohen, J. (1988). Statistical power analysis for the behavioral sciences. Statistical Power Analysis for the Behavioral Sciences. doi:10.1234/12345678

Collip, D., Wigman, J. T. W., Myin-Germeys, I., Jacobs, N., Derom, C., Thiery, E., Wichers, M., et al. (2013). From epidemiology to daily life: linking daily life stress reactivity to persistence of psychotic experiences in a longitudinal general population study. PloS ONE, 8(4), e62688. doi:10.1371/journal.pone.0062688

Croft, R. J., Mackay, A. J., Mills, A. T. D., \& Gruzelier, J. G. H. (2001). The relative contributions of ecstasy and cannabis to cognitive impairment. Psychopharmacology, 153(3), 373-379. doi:10.1007/s002130000591

Cuttler, C., Graf, P., Pawluski, J. L., \& Galea, L. A. M. (2011). Everyday life memory deficits in pregnant women. Can. J. Exp. Psychol., 65(1), 27-37. doi:10.1037/a0022844

David, A. S., Zammit, S., Lewis, G., Dalman, C., \& Allebeck, P. (2008). Impairments in cognition across the spectrum of psychiatric disorders: evidence from a Swedish conscript cohort. Schizophrenia bulletin, 34(6), 1035-41. doi:10.1093/schbul/sbn028

De La Torre, R., Farré, M., Ortuño, J., Mas, M., Brenneisen, R., Roset, P. N., Segura, J., et al. (2000). Non-linear pharmacokinetics of MDMA ('ecstasy') in humans. British Journal of Clinical Pharmacology, 49(2), 104-109. doi:10.1046/j.1365-2125.2000.00121.x

Donohoe, G., Gill, M., Corvin, A. P., Hayden, J., McGlade, N., O’Grada, C., Burke, T., et al. (2009). Is "clinical" insight the same as "cognitive" insight in schizophrenia? Journal of the International Neuropsychological Society, 15(3), 471-475.

doi:10.1017/S1355617709090559

Downey, L. A., King, R., Papafotiou, K., Swann, P., Ogden, E., Boorman, M., \& Stough, C. (2013). The effects of cannabis and alcohol on simulated driving: Influences of dose and experience. Accident; analysis and prevention, 50, 879-86. doi:10.1016/j.aap.2012.07.016

Farrin, L., Hull, L., Unwin, C., \& Wykes, T. (2003). Effects of depressed mood on objective and subjective measures of attention. Journal of Neuropsychiatry and Clinical Neurosciences, 15(1), 98 - 104. doi:10.1176/appi.neuropsych.15.1.98

Fisk, J. E., \& Montgomery, C. (2008). Real-world memory and executive processes in cannabis users and non-users. Journal of Psychopharmacology, 22(7), 727-36. doi:10.1177/0269881107084000 
Grisham, J. R., Norberg, M. M., Williams, A. D., Certoma, S. P., \& Kadib, R. (2010). Categorization and cognitive deficits in compulsive hoarding. Behaviour Research and Therapy, 48(9), 866-72. doi:10.1016/j.brat.2010.05.011

Hadjiefthyvoulou, F., Fisk, J. E., Montgomery, C., \& Bridges, N. (2011). Everyday and prospective memory deficits in ecstasy/polydrug users. Journal of Psychopharmacology, 25(4), 453-464. doi:10.1177/0269881109359101

Heffernan, T. M., Jarvis, H., Rodgers, J., Scholey, A. B., \& Ling, J. (2001). Prospective memory, everyday cognitive failure and central executive function in recreational users of Ecstasy. Human Psychopharmacology, 16(8), 607-612. doi:10.1002/hup.349

Heishman, S. J., Kleykamp, B. A., \& Singleton, E. G. (2010). Meta-analysis of the acute effects of nicotine and smoking on human performance. Psychopharmacology, 210(4), 453-469. doi: $10.1002 / j$ ts. 2490050305

Herman, J. L. (1992). Complex PTSD: A syndrome in survivors of prolonged and repeated trauma. Journal of Traumatic Stress, 5(3), 377-391.

Ishigami, Y., \& Klein, R. M. (2009). Are individual differences in absentmindedness correlated with individual differences in attention? Journal of Individual Differences, 30(4), 220-237. doi:10.1027/1614-0001.30.4.220

Kanai, R., Dong, M. Y., Bahrami, B., \& Rees, G. (2011). Distractibility in daily life is reflected in the structure and function of human parietal cortex. Journal of Neuroscience, 31(18), 6620-6626. doi:10.1523/JNEUROSCI.5864-10.2011

Kane, M. J., Brown, L. H., McVay, J. C., Silvia, P. J., Myin-Germeys, I., \& Kwapil, T. R. (2007). For whom the mind wanders, and when: an experience-sampling study of working memory and executive control in daily life. Psychological Science, 18(7), 614-621. doi:10.1111/j.1467-9280.2007.01948.x

Klugman, A., \& Gruzelier, J. (2003). Chronic cognitive impairment in users of "ecstasy" and cannabis. World Psychiatry, 2(3), 184-90.

Koso, M., Sarač-Hadzihalilovic, A., \& Hansen, S. (2012). Neuropsychological performance, psychiatric symptoms, and everyday cognitive failures in Bosnian ex-servicemen with posttraumatic stress disorder. Review of Psychology, 19(2), 131-139.

Lange, S., \& Süß, H.-M. (2014). Measuring slips and lapses when they occur - ambulatory assessment in application to cognitive failures. Conscious. Cogn., 24, 1-11. doi:10.1016/j.concog.2013.12.008

Larson, G. E., \& Merritt, C. R. (1991). Can Accidents be Predicted? An Empirical Test of the Cognitive Failures Questionnaire. Applied Psychology, 40(1), 37-45. doi:10.1111/j.14640597.1991.tb01356.x 
Ling, J., Heffernan, T. M., Buchanan, T., Rodgers, J., Scholey, A. B., \& Parrott, A. C. (2003). Effects of alcohol on subjective ratings of prospective and everyday memory deficits. Alcoholism, Clinical and Experimental Research, 27(6), 970-4. doi:10.1097/01.ALC.0000071741.63467.CB

Lipsey, M. W., \& Wilson, D. B. (2001). Practical meta-analysis. Applied Social Research Methods Series, 49, 264.

Lyvers, M., \& Tobias-Webb, J. (2010). Effects of acute alcohol consumption on executive cognitive functioning in naturalistic settings. Addictive Behaviors, 35(11), 1021-1028. doi:10.1016/j.addbeh.2010.06.022

MacQueen, G. M., Galway, T. M., Hay, J., Young, L. T., \& Joffe, R. T. (2002). Recollection memory deficits in patients with major depressive disorder predicted by past depressions but not current mood state or treatment status. Psychological Medicine, 32(02), 251-258. doi:10.1017/S0033291701004834

Mahoney, A., Dalby, J., \& King, M. (1998). Cognitive failures and stress. Psychological Reports, 82(3), 1432-1434. doi:10.2466/PR0.82.3.1432-1434

Manning, V., Teo, H. C., Guo, S., Wong, K. E., \& Li, T.-K. (2016). Neurocognitive functioning and treatment outcome following detoxification among Asian alcohol-dependent inpatients. Substance Use \& Misuse, 51(2), 193-205. doi:10.3109/10826084.2015.1092985

Marczinski, C. A., Harrison, E. L. R., \& Fillmore, M. T. (2008). Effects of alcohol on simulated driving and perceived driving impairment in binge drinkers. Alcoholism, clinical and experimental research, 32(7), 1329-37. doi:10.1111/j.1530-0277.2008.00701.x

Matthews, G, Coyle, K., \& Craig, A. (1990). Multiple factors of cognitive failures and their relationship with stress vulnerability. Journal of Psychopathology and Behavioral Assessment, 12(1), 49 - 65 .

Matthews, Gerald, \& Wells, A. (1988). Relationships between anxiety, self-consciousness, and cognitive failure. Cognition \& Emotion, 2(2), 123-132. doi:10.1080/02699938808408069

Maylor, E. (1990). Age, blocking and the tip of the tongue state. British Journal of Psychology, $81,123-34$.

McDermott, L. M., \& Ebmeier, K. P. (2009). A meta-analysis of depression severity and cognitive function. Journal of Affective Disorders, 119(1-3), 1-8. doi:10.1016/j.jad.2009.04.022

McVay, J. C., Kane, M. J., \& Kwapil, T. R. (2009). Tracking the train of thought from the laboratory into everyday life: an experience-sampling study of mind wandering across controlled and ecological contexts. Psychonomic Bulletin and Review, 16(5), 857-63. doi:10.3758/PBR.16.5.857 
Mecacci, L., Righi, S., \& Rocchetti, G. (2004). Cognitive failures and circadian typology. Personality and Individual Differences, 37(1), 107-113. doi:10.1016/j.paid.2003.08.004

Merckelbach, H., Muris, P., Nijman, H., \& De Jong, P. J. (1996). Self-reported cognitive failures and neurotic symptomatology. Personality and Individual Differences, 20(6), 715-724. doi:10.1016/0191-8869(96)00024-4

Montgomery, C., \& Fisk, J. E. (2007). Everyday memory deficits in ecstasy-polydrug users. Journal of Psychopharmacology, 21(7), 709-17. doi:10.1177/0269881107077220

Myin-Germeys, I., Delespaul, P., \& Van Os, J. (2003). The experience sampling method in psychosis research. Current Opinion in Psychiatry, 16, 33-38. doi:10.1097/00001504200304002-00006

Neupert, S. D., Mroczek, D. K., \& Spiro, A. (2008). Neuroticism moderates the daily relation between stressors and memory failures. Psychology and Aging, 23(2), 287-296.

doi:10.1037/0882-7974.23.2.287

Palmer, B. W., Heaton, R. K., Paulsen, J. S., Kuck, J., Braff, D., Harris, M. J., Zisook, S., et al. (1997). Is it possible to be schizophrenic yet neuropsychologically normal? Neuropsychology, 11(3), 437-446. doi:10.1037/0894-4105.11.3.437

Parrott, A., \& Kaye, F. (1999). Daily uplifts, hassles, stresses and cognitive failures: in cigarette smokers, abstaining smokers, and non-smokers. Behavioral Pharamacology, 10(6-7), 639646.

Payne, T. W., \& Schnapp, M. A. (2014). The relationship between negative affect and reported cognitive failures. Depression Research and Treatment, 2014, 396195. doi:10.1155/2014/396195

Peterson, J. B., Rothfleisch, J., Zelazo, P. D., \& Pihl, R. O. (1990). Acute alcohol intoxication and cognitive functioning. Journal of studies on alcohol, 51(2), 114-122. doi:10.15288/jsa.1990.51.114

Pfeifer, S., Van Os, J., Hanssen, M., Delespaul, P., \& Krabbendam, L. (2009). Subjective experience of cognitive failures as possible risk factor for negative symptoms of psychosis in the general population. Schizophrenia Bulletin, 35(4), 766-74. doi:10.1093/schbul/sbn004

Preiss, M., Kramska, L., Dockalova, E., Holubova, M., \& Kucerova, H. (2010). Attentional networks in euthymic patients with unipolar depression. European Psychiatrysychiatry, 25(2), 69-74. doi:10.1016/j.eurpsy.2009.08.007

Reason, J. (1979). Actions not as planned: the price of automatization. In G. Underwood \& R. Stevens (Eds.), Aspects of Consciousness (pp. 67-89). London, UK: Academic Press Inc. Ltd. 
Reason, J. (1993). Self-report questionnaires in cognitive psychology: have they delivered the goods? In A. B. and L. Weiskrantz (Ed.), Attention: Selection, Awareness and Control, Oxford: Clarendon Press (pp. 406-423). Clarendon: Oxford University Press.

Robertson, I. H., Manly, T., Andrade, J., Baddeley, B. T., \& Yiend, J. (1997). “Oops!”: performance correlates of everyday attentional failures in traumatic brain injured and normal subjects. Neuropsychologia, 35(6), 747-58.

Rock, P. L., Roiser, J. P., Riedel, W. J., \& Blackwell, A. D. (2014). Cognitive impairment in depression: a systematic review and meta-analysis. Psychological medicine, 44(10), 2029 40. doi:10.1017/S0033291713002535

Rodgers, J. (2000). Cognitive performance amongst recreational users of "ecstasy". Psychopharmacology, 151(1), 19-24. doi:10.1007/s002130000467

Schleicher, H. E., Harris, K. J., Catley, D., \& Nazir, N. (2010). The role of depression and negative affect regulation expectancies in tobacco smoking among college students. Journal of American College Health, 57(5), 507-12. doi:10.3200/JACH.57.5.507-512

Schouws, S., Comijs, H., Stek, M., \& Beekman, A. (2012). Self-reported cognitive complaints in elderly bipolar patients. American Journal of Geriatric Psychiatry, 20(8), 700-706. doi:10.1097/JGP.0b013e31822ccd27

Schultze-Lutter, F., Klosterkötter, J., \& Ruhrmann, S. (2014). Improving the clinical prediction of psychosis by combining ultra-high risk criteria and cognitive basic symptoms. Schizophrenia Research, 154(1-3), 100-6. doi:10.1016/j.schres.2014.02.010

Schweizer, T. A., Vogel-Sprott, M., Danckert, J., Roy, E. A., Skakum, A., \& Broderick, C. E. (2006). Neuropsychological profile of acute alcohol intoxication during ascending and descending blood alcohol concentrations. Neuropsychopharmacology, 31(6), 1301-1309. doi:10.1038/sj.npp.1300941

Smilek, D., Carriere, J. S. A., \& Cheyne, J. A. (2010a). Failures of sustained attention in life, lab, and brain : ecological validity of the SART. Neuropsychologia, 48(9), 2564-2570. doi:10.1016/j.neuropsychologia.2010.05.002

Smilek, D., Carriere, J. S. A., \& Cheyne, J. A. (2010b). Failures of sustained attention in life, lab, and brain: Ecological validity of the SART. NEUROPSYCHOLOGIA, 48(9), 2564-2570. doi:10.1016/j.neuropsychologia.2010.05.002

Smith, G., Della Sala, S., Logie, R. H., \& Maylor, E. A. (2000). Prospective and retrospective memory in normal ageing and dementia: a questionnaire study. Mem., 8(5), 311-321. doi:10.1080/09658210050117735 
Sullivan, B., \& Payne, T. W. (2007). Affective disorders and cognitive failures: a comparison of seasonal and nonseasonal depression. The American Journal of Psychiatry, 164(11), 16637. doi:10.1176/appi.ajp.2007.06111792

Suls, J., \& Martin, R. (2005). The daily life of the garden-variety neurotic: Reactivity, stressor exposure, mood spillover, and maladaptive coping. Journal of Personality, 73(6), 14851509. doi:10.1111/j.1467-6494.2005.00356.x

Van den Bosch, R. J., Rombouts, R., \& Van Asma, M. J. O. (1993). Subjective cognitive dysfunction in schizophrenic and depressed patients. Comprehensive Psychiatry, 34(2), 130-136. doi:10.1016/0010-440X(93)90058-C

Wallace, J. C., Vodanovich, S. J., \& Restino, B. M. (2003). Predicting cognitive failures from boredom proneness and daytime sleepiness scores : an investigation within military and undergraduate samples. Personality and Individual Differences, 34(4), 635-644. doi:10.1016/S0191-8869(02)00050-8

Wan, L., Friedman, B. H., Boutros, N. N., \& Crawford, H. J. (2008). Smoking status affects men and women differently on schizotypal traits and cognitive failures. Personality and Individual Differences, 44(2), 425-435. doi:10.1016/j.paid.2007.09.002

Weaver, T., Madden, P., Charles, V., Stimson, G., Renton, A., Tyrer, P., Barnes, T., et al. (2003). Comorbidity of substance misuse and mental illness in community mental health and substance misuse services. The British Journal of Psychiatry, 183(4), 304-313. doi:10.1192/bjp.183.4.304

Wilhelm, O., Witthoeft, M., \& Schipolowski, S. (2010). Self-Reported Cognitive Failures Competing Measurement Models and Self-Report Correlates. JOURNAL OF INDIVIDUAL DIFFERENCES, 31(1), 1-14. doi:10.1027/1614-0001/a000001

Wilhelm, O., Witthöft, M., \& Schipolowski, S. (2010). Self-reported cognitive failures: competing measurement models and self-report correlates. Journal of Individual Differences, 31(1), 1-14. doi:10.1027/1614-0001/a000001 
COGNITIVE FAILURES, PSYCHOLOGICAL DISORDERS, SUBSTANCE USE

Table 1

Associations Between Affective Disorders and Cognitive Failures.

\begin{tabular}{|c|c|c|c|}
\hline Reference & Study population & Findings & $\begin{array}{l}\text { Group differences: } p \text { - } \\
\text { value; Cohen's } d[95 \% \mathrm{CI}]\end{array}$ \\
\hline \multicolumn{4}{|c|}{ Affective disorders } \\
\hline $\begin{array}{l}\text { MacQueen, } \\
\text { Galway, Hay, } \\
\text { Young, \& } \\
\text { Joffe (2002) }\end{array}$ & $\begin{array}{l}40 \text { patients with past or current } \\
\text { major depressive disorder } \\
\text { (SCID for DSM-IV). } \\
\text { Mean age } 36.2 \text { years; } 30 \text { males. }\end{array}$ & $\begin{array}{l}\text { Patients reported more cognitive failures, and this } \\
\text { predicted poorer memory performance } \\
\text { independent of mood. There was no difference in } \\
\text { failures reported by symptomatic versus improved } \\
\text { patients (i.e. antidepressant non-responders versus } \\
\text { responders). }\end{array}$ & $\begin{array}{l}\text { Clinical vs. control: } p<.001 ; \\
1.77[1.25,2.28]^{* * * *}\end{array}$ \\
\hline $\begin{array}{l}\text { Farrin, Hull, } \\
\text { Unwin, \& } \\
\text { Wykes (2003) }\end{array}$ & $\begin{array}{l}43 \text { UK military servicemen with } \\
\text { mild depression (BDI > 10). } \\
\text { Mean age } 35.79 \text { years. }\end{array}$ & $\begin{array}{l}\text { Depressed men performed worse on an attention } \\
\text { task and also reported higher CFQ scores than } \\
\text { non-depressed men. }\end{array}$ & $\begin{array}{l}\text { Clinical vs. control: } p< \\
.0001 ; 1.57[1.13,2.02]^{* * * *}\end{array}$ \\
\hline $\begin{array}{l}\text { Burdick, } \\
\text { Endick, \& }\end{array}$ & $\begin{array}{l}37 \text { outpatients with bipolar I or } \\
\text { II in various phases of illness }\end{array}$ & $\begin{array}{l}75 \% \text { of patients displayed mild } \\
\text { neuropsychological impairment, but self-reported }\end{array}$ & $\begin{array}{l}\text { CFQ - depression } \\
\text { relationship }{ }^{\text {a }} p=.06 ; 0.67 * *\end{array}$ \\
\hline
\end{tabular}


COGNITIVE FAILURES, PSYCHOLOGICAL DISORDERS, SUBSTANCE USE

\begin{tabular}{|c|c|c|c|}
\hline $\begin{array}{l}\text { Goldberg } \\
(2005)\end{array}$ & $\begin{array}{l}\text { (SCID for DSM-IV). } \\
\text { Mean age } 46.2 \text { years; } 20 \text { males. }\end{array}$ & $\begin{array}{l}\text { cognitive failures did not correlate significantly } \\
\text { with measures of mood or objective outcomes. }\end{array}$ & $\begin{array}{l}\text { CFQ - mania relationship }{ }^{\mathrm{a}}: \\
p=.09 ;-0.59 * *\end{array}$ \\
\hline $\begin{array}{l}\text { Sullivan \& } \\
\text { Payne (2007) }\end{array}$ & $\begin{array}{l}26 \text { individuals with seasonal } \\
\text { depression, } 8 \text { with major } \\
\text { depressive disorder (Seasonal } \\
\text { Pattern Assessment } \\
\text { Questionnaire > 11; BDI-II } \\
>17 \text { ). } \\
\text { Age } 18-22 \text { years; } 4 \text { males. }\end{array}$ & $\begin{array}{l}\text { Both patient groups reported greater experiences } \\
\text { of cognitive failures than healthy individuals. } \\
\text { There was no difference between the two } \\
\text { depression subtypes. }\end{array}$ & $\begin{array}{l}\text { MDD vs. control: } \\
p<.001 ; 1.68[0.89, \\
2.47]^{* * * *} \\
\text { MDD vs. SAD: } \\
p>.05 ; 0.56[-0.24,1.37]^{* *} \\
\text { SAD vs. control: } \\
p<.001 ; 1.12[0.63,1.61]^{* * *}\end{array}$ \\
\hline $\begin{array}{l}\text { Preiss, } \\
\text { Kramska, } \\
\text { Dockalova, } \\
\text { Holubova, \& } \\
\text { Kucerova } \\
\text { (2010) }\end{array}$ & $\begin{array}{l}32 \text { outpatients with depression, } \\
\text { currently in euthymic stage } \\
\text { (MINI). } \\
\text { Mean age } 46.8 \text { years; } 12 \text { males. }\end{array}$ & $\begin{array}{l}\text { Found no differences in attentional networks in } \\
\text { euthymic patients compared with controls. } \\
\text { Attentional performance did not correlate with } \\
\text { CFQ scores. Group comparisons for CFQ scores } \\
\text { were not reported. }\end{array}$ & $\begin{array}{l}\text { Did not report on group } \\
\text { differences or relationship } \\
\text { between CFQ and diagnostic } \\
\text { measures. }\end{array}$ \\
\hline Schouws, & 101 elderly patients with & Patients reported no greater failures than controls & Clinical vs. control: $p=$ \\
\hline
\end{tabular}


COGNITIVE FAILURES, PSYCHOLOGICAL DISORDERS, SUBSTANCE USE

\begin{tabular}{|l|l|l|l|}
\hline Comijs, Stek, & bipolar, currently in euthymic & despite exhibiting impairment in several objective & $0.36 ; 0.14[-0.02,0.04]$ \\
$\&$ Beekman & stage (SCID for DSM-IV). & domains. Patients with worse objective & \\
$(2012)$ & Mean age 69.3 years; 50 males. & performance reported fewer cognitive failures than & \\
& & those with better performance. & \\
\hline
\end{tabular}

$p$ values for some studies were not reported and thus are not included in the table. ${ }^{1}=r$ coefficients transformed into Cohen's $d$; CIs not calculated. Classification of effect sizes: trivial (Cohen's $\mathrm{d} \leq .2) ;{ }^{*}$ small (Cohen's $\mathrm{d}>.2$ ); ${ }^{* *}$ moderate (Cohen's $\mathrm{d}>.5$ ); *** large (Cohen's d > .8); **** very large (Cohen's d > 1.3). 
COGNITIVE FAILURES, PSYCHOLOGICAL DISORDERS, SUBSTANCE USE

Table 2

Associations Between Non-Affective Disorders and Cognitive Failures.

\begin{tabular}{|c|c|c|c|}
\hline Reference & Study population & Findings & $\begin{array}{l}\text { Group differences: } p \text { - } \\
\text { value; Cohen's } d[95 \% \mathrm{CI}]\end{array}$ \\
\hline \multicolumn{4}{|c|}{ Anxiety disorders } \\
\hline $\begin{array}{l}\text { Merckelbach, } \\
\text { Muris, } \\
\text { Nijman, \& de } \\
\text { Jong (1996) }\end{array}$ & $\begin{array}{l}3 \text { studies including } 30 \text { females } \\
\text { with spider phobias and } 224 \\
\text { outpatients with anxiety (panic } \\
\text { disorder, GAD, social phobia, } \\
\text { OCD, atypical anxiety) or } \\
\text { depression (SCID for DSM-III- } \\
\text { R). } \\
\text { Mean age } 31 \text { years; } 30 \text { females } \\
\text { only - mean age } 35 \text { years; } 105 \\
\text { males. }\end{array}$ & $\begin{array}{l}\text { CFQ scores were correlated with general } \\
\text { psychopathological symptom severity. Clinically } \\
\text { anxious individuals and those with OCD reported } \\
\text { fewer failures than healthy controls, whilst } \\
\text { clinically depressed individuals reported more } \\
\text { than controls. Individuals with a phobia did not } \\
\text { differ to controls in their CFQ scores. }\end{array}$ & $\begin{array}{l}\text { Spider phobic vs. control: } \\
-0.01[-0.51,-0.49] \\
\text { Anxiety vs. control: } \\
-0.39[-0.64,-0.14]^{*} \\
\text { Depressed vs. control: } \\
0.91[0.43,1.41]^{* * *} \\
\text { OCD vs. control: }-0.3[-0.68, \\
0.08]^{*}\end{array}$ \\
\hline Grisham, & 23 patients with compulsive & Patients reported more cognitive failures than & Hoarding vs. clinical \\
\hline
\end{tabular}


COGNITIVE FAILURES, PSYCHOLOGICAL DISORDERS, SUBSTANCE USE

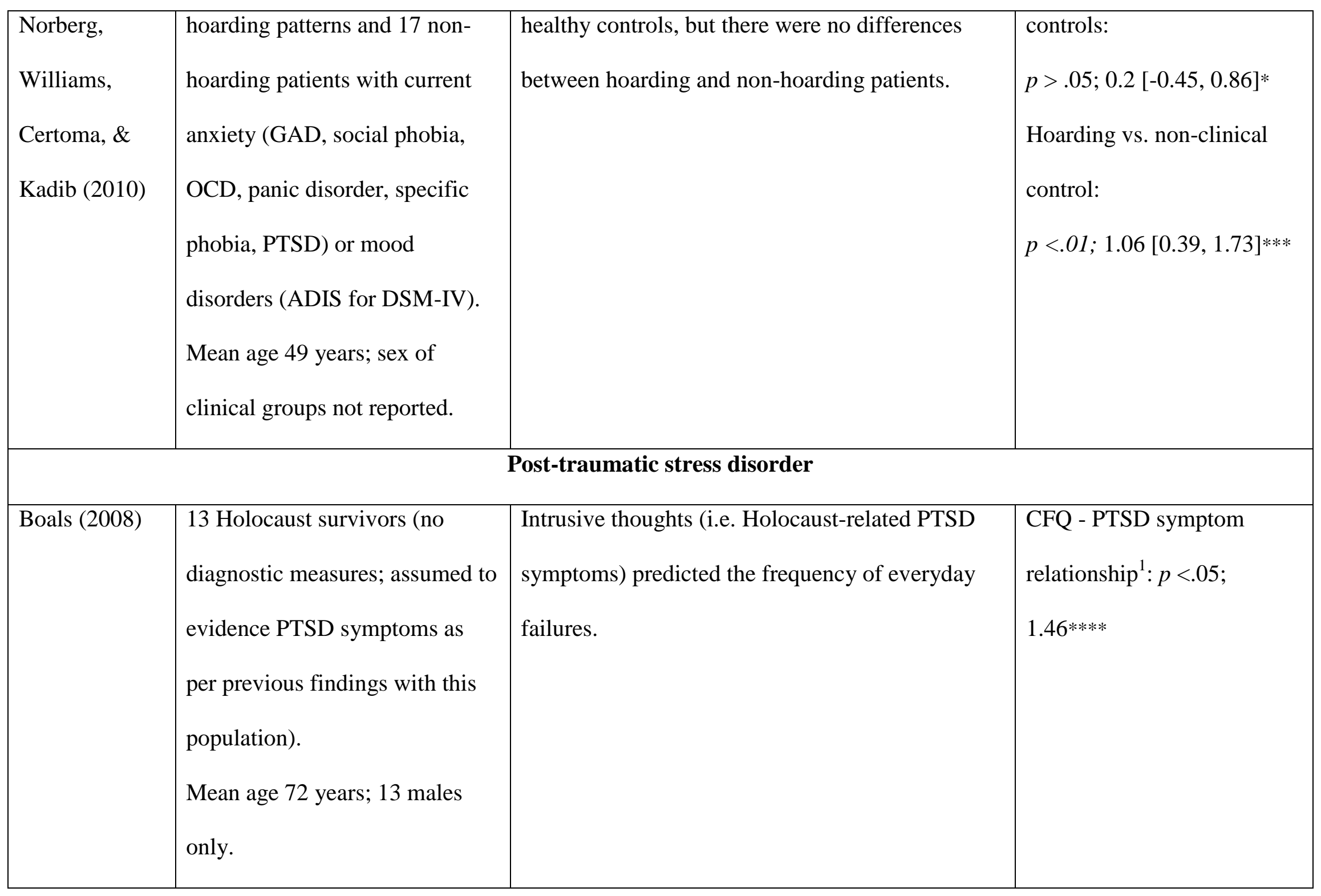


COGNITIVE FAILURES, PSYCHOLOGICAL DISORDERS, SUBSTANCE USE

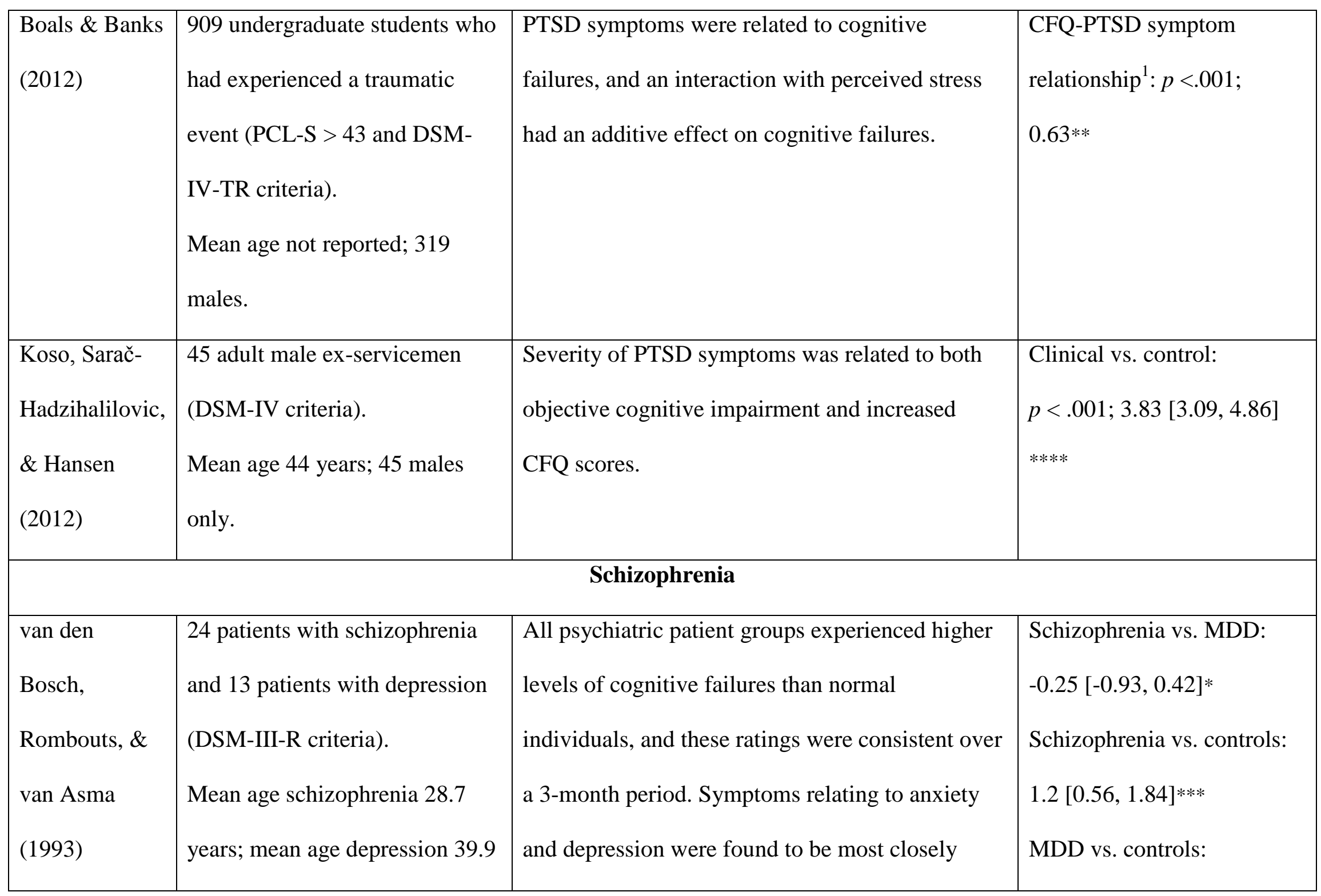


COGNITIVE FAILURES, PSYCHOLOGICAL DISORDERS, SUBSTANCE USE

\begin{tabular}{|c|c|c|c|}
\hline & $\begin{array}{l}\text { years; sex of clinical groups not } \\
\text { reported. }\end{array}$ & associated with everyday failures. & $1.72[0.91,2.53] * * * *$ \\
\hline $\begin{array}{l}\text { Donohoe et al. } \\
\text { (2009) }\end{array}$ & $\begin{array}{l}51 \text { stabilised patients with } \\
\text { chronic schizophrenia (SCID for } \\
\text { DSM-IV). } \\
\text { Mean age } 39.8 \text { years; } 20 \text { males. }\end{array}$ & $\begin{array}{l}\text { Patients did not report more cognitive failures than } \\
\text { controls. Cognitive failures and objective } \\
\text { neuropsychological assessment correlated only for } \\
\text { some patients with good clinical insight (i.e. good } \\
\text { awareness of illness). Overall, clinical insight and } \\
\text { cognitive insight (cognitive failures correlate with } \\
\text { objective outcome) not linked. }\end{array}$ & $\begin{array}{l}\text { Clinical vs. controls: } \\
p \text { not reported; } 0.33 \text { [-0.06, } \\
0.71] *\end{array}$ \\
\hline
\end{tabular}

$p$ values for some studies were not reported and thus are not included in the table. ${ }^{1}=r$ coefficients transformed into Cohen's $d$; CIs not calculated. Classification of effect sizes: trivial (Cohen's $\mathrm{d} \leq .2)$; * small (Cohen's d > .2); ** moderate (Cohen's $\mathrm{d}>.5$ ); *** large $($ Cohen's d > .8); **** very large (Cohen's d > 1.3). 
COGNITIVE FAILURES, PSYCHOLOGICAL DISORDERS, SUBSTANCE USE

Table 3

Associations Between Substance Use and Cognitive Failures.

\begin{tabular}{|c|c|c|c|}
\hline Reference & Study population & Findings & $\begin{array}{l}\text { Group differences: } p \text { - } \\
\text { value; Cohen's } d[95 \% \mathrm{CI}]\end{array}$ \\
\hline \multicolumn{4}{|c|}{ Nicotine } \\
\hline $\begin{array}{l}\text { Parrott \& Kaye } \\
\text { (1999) }\end{array}$ & $\begin{array}{l}25 \text { each of smokers (mean } \\
\text { age } 24.3 \text { years; } 15 \text { male), } \\
\text { abstaining smokers (mean } \\
\text { age } 23.5 \text { years; } 11 \text { male), } \\
\text { and non-smokers (mean } \\
\text { age } 26.5 ; 7 \text { male). }\end{array}$ & $\begin{array}{l}\text { Abstaining smokers reported greater stress, lower } \\
\text { arousal, less pleasure, and more cognitive failures } \\
\text { than both non-smokers and non-abstaining } \\
\text { smokers. There were no differences between these } \\
\text { latter groups. }\end{array}$ & $\begin{array}{l}\text { Smokers vs. non-smokers: } \\
0.40[-0.16,0.96] * \\
\text { Abstaining vs. smokers: } \\
0.89[0.31,1.47] * * * \\
\text { Abstaining vs. non-smokers: } \\
1.29[0.68,1.90] * * *\end{array}$ \\
\hline $\begin{array}{l}\text { Wan, Friedman, } \\
\text { Boutros, \& } \\
\text { Crawford (2008) }\end{array}$ & $\begin{array}{l}440 \text { non-smokers ( } 170 \\
\text { males), } 107 \text { daily smokers } \\
\text { (43 males), and } 47 \text { non- } \\
\text { daily smokers ( } 18 \text { males). } \\
\text { Overall mean age } 19.01\end{array}$ & $\begin{array}{l}\text { Daily smokers reported greater frequencies of } \\
\text { cognitive slips, and non-daily smokers reported } \\
\text { more slips in memory than non-smokers. }\end{array}$ & $\begin{array}{l}\text { Daily vs. non-daily: } \\
-0.02[-0.42,0.37] \\
\text { Daily vs. non-smokers: } \\
0.31[0.08 ., 0.54] * \\
\text { Non-daily vs. non-smokers: }\end{array}$ \\
\hline
\end{tabular}


COGNITIVE FAILURES, PSYCHOLOGICAL DISORDERS, SUBSTANCE USE

\begin{tabular}{|c|c|c|c|}
\hline & years. & & $0.33[-0.02,0.68] *$ \\
\hline \multicolumn{4}{|c|}{ Alcohol } \\
\hline $\begin{array}{l}\text { Manning, Teo, Guo, } \\
\text { Wong, \& Li (2016) }\end{array}$ & $\begin{array}{l}30 \text { post-detox alcohol- } \\
\text { dependent patients (DSM- } \\
\text { IV-TR criteria). } \\
\text { Mean age } 49.5 \text { years; } 30 \\
\text { male only. }\end{array}$ & $\begin{array}{l}\text { Alcohol dependence diagnosis post-inpatient } \\
\text { detoxification was associated with increased CFQ } \\
\text { scores relative to controls. }\end{array}$ & $\begin{array}{l}\text { Not calculable from } \\
\text { provided data. }\end{array}$ \\
\hline \multicolumn{4}{|c|}{ Cannabis, ecstasy and polydrug use } \\
\hline Rodgers (2000) & $\begin{array}{l}15 \text { ecstasy users (mean age } \\
31.4 \text { years; } 7 \text { males), } 15 \\
\text { cannabis users (mean age } \\
30.25 \text { years; } 7 \text { males). }\end{array}$ & $\begin{array}{l}\text { Verbal memory deficits were identified in both } \\
\text { ecstasy and cannabis users, whilst only ecstasy } \\
\text { users exhibited impaired delayed memory. } \\
\text { Subjective impairment did not significantly differ } \\
\text { between groups. }\end{array}$ & $\begin{array}{l}\text { Ecstasy vs. cannabis: } \\
p>.05 ; 0.54[-0.19,1.27] * * \\
\text { Ecstasy vs. control: } \\
p>.05 ; 0.01[-0.71,0.72] \\
\text { Cannabis vs. control: } \\
p>.05 ;-0.53[-1.25,0.20] \\
* *\end{array}$ \\
\hline Heffernan, Jarvis, & 3 studies comprising 91 & Ecstasy users reported more errors in prospective & Same data as above study. \\
\hline
\end{tabular}


COGNITIVE FAILURES, PSYCHOLOGICAL DISORDERS, SUBSTANCE USE

\begin{tabular}{|c|c|c|c|}
\hline $\begin{array}{l}\text { Rodgers, Scholey, \& } \\
\text { Ling (2001) }\end{array}$ & $\begin{array}{l}\text { regular ecstasy users. } \\
\text { Mean age } 26.6 \text { years; } 52 \\
\text { males. }\end{array}$ & $\begin{array}{l}\text { memory in everyday life than controls; this } \\
\text { matched with objective performance. This was not } \\
\text { generalizable to all aspects of everyday cognition, } \\
\text { with no differences in ratings on the CFQ. }\end{array}$ & \\
\hline $\begin{array}{l}\text { Montgomery \& Fisk } \\
\text { (2007) }\end{array}$ & $\begin{array}{l}43 \text { ecstasy/polydrug users. } \\
\text { Mean age } 21.56 \text { years; } 24 \\
\text { males. }\end{array}$ & $\begin{array}{l}\text { Ecstasy/polydrug users exhibited greater } \\
\text { subjective (also supported by informant) and } \\
\text { objective deficits than non-users; however } \\
\text { cannabis was found to be the drug most closely } \\
\text { linked to users' everyday problems. }\end{array}$ & $\begin{array}{l}\text { Ecstasy/polydrug vs. } \\
\text { controls: } \\
p \text { not reported; } 0.51[0.12 \\
0.91] * *\end{array}$ \\
\hline $\begin{array}{l}\text { Fisk \& Montgomery } \\
\text { (2008) }\end{array}$ & $\begin{array}{l}46 \text { cannabis-only users. } \\
\text { Mean age } 21 \text { years; sex } \\
\text { not reported. }\end{array}$ & $\begin{array}{l}\text { Relative impairment in real-world memory } \\
\text { functioning was identified in cannabis users, } \\
\text { although this was not found in objective measures } \\
\text { of executive processes. Significant others also } \\
\text { observed more failures in users than non-users. }\end{array}$ & $\begin{array}{l}\text { Cannabis vs. control: } \\
p=.02 ; 0.59[0.08,1.13] * *\end{array}$ \\
\hline $\begin{array}{l}\text { Hadjiefthyvoulou, } \\
\text { Fisk, Montgomery, }\end{array}$ & $\begin{array}{l}42 \text { ecstasy/polydrug users. } \\
\text { Mean age } 21.67 \text { years; } 14\end{array}$ & $\begin{array}{l}\text { Regular illicit drug use was associated with } \\
\text { deficits in objective and subjective prospective }\end{array}$ & $\begin{array}{l}\text { Ecstasy/polydrug vs. } \\
\text { control: }\end{array}$ \\
\hline
\end{tabular}


COGNITIVE FAILURES, PSYCHOLOGICAL DISORDERS, SUBSTANCE USE

\begin{tabular}{|l|l|l|l|}
\hline \& Bridges (2011) & males. & $\begin{array}{l}\text { memory, but not cognitive failures more } \\
\text { generally. Cognitive failures correlated with } \\
\text { recency of ecstasy use. }\end{array}$ & $p>05 ; 0.25[-0.22,0.72] *$ \\
& & & \\
\hline
\end{tabular}

$p$ values for some studies were not reported and thus are not included in the table. Classification of effect sizes: trivial (Cohen's $\mathrm{d} \leq$ $.2)$; * small (Cohen's d > .2); ** moderate (Cohen's d > .5); *** large (Cohen's d > .8); **** very large (Cohen's d > 1.3). 
COGNITIVE FAILURES, PSYCHOLOGICAL DISORDERS, SUBSTANCE USE

Table 4

Comparison of Objective Cognitive Assessment and Subjective Cognitive Failures in Psychological Disorders and Substance Use.

\begin{tabular}{|c|c|c|c|c|c|c|c|}
\hline Psychological disorders & & & & & & & \\
\hline Reference & Disorder & $\begin{array}{c}\text { Overall } \\
\text { cognition }\end{array}$ & Attention & $\begin{array}{l}\text { Executive } \\
\text { function }\end{array}$ & Memory & $\begin{array}{l}\text { Working } \\
\text { memory }\end{array}$ & $\begin{array}{l}\text { Verbal } \\
\text { function }\end{array}$ \\
\hline $\begin{array}{l}\text { MacQueen, Galway, Hay, Young, \& } \\
\text { Joffe (2002) }\end{array}$ & Depression & & & & $\mathrm{X}$ & & \\
\hline Farrin, Hull, Unwin, \& Wykes (2003) & Depression & & $\sqrt{ }$ & & & & \\
\hline $\begin{array}{l}\text { Preiss, Kramska, Dockalova, Holubova, } \\
\text { \& Kucerova (2010) }\end{array}$ & Depression & & $\mathrm{X}$ & & & & \\
\hline Burdick, Endick, \& Goldberg (2005) ${ }^{1}$ & Bipolar & & $\mathrm{X}$ & $\mathrm{X}$ & $\mathrm{X}$ & & \\
\hline $\begin{array}{l}\text { Schouws, Comijs, Stek, \& } \\
\text { Beekman (2012) }\end{array}$ & Bipolar (elderly) & & $\mathrm{X}$ & $\sqrt{ }$ & $\mathrm{X}$ & & $\mathrm{X}$ \\
\hline $\begin{array}{l}\text { Grisham, Norberg, Williams, Certoma, } \\
\text { \& Kadib (2010) }\end{array}$ & $\begin{array}{l}\text { Compulsive hoarding } \\
\text { patterns }\end{array}$ & $\mathrm{X}$ & & $\mathrm{X}$ & & & \\
\hline Koso, Sarač-Hadzihalilovic, \& Hansen & PTSD & & & J & $\sqrt{ }$ & & $\sqrt{ }$ \\
\hline
\end{tabular}


COGNITIVE FAILURES, PSYCHOLOGICAL DISORDERS, SUBSTANCE USE

\begin{tabular}{|c|c|c|c|c|c|c|c|}
\hline$(2012)$ & & & & & & & \\
\hline Donohoe et al. (2009) & Schizophrenia & $\mathrm{X}$ & $\sqrt{ } *$ & & $\sqrt{ } *$ & $\mathrm{X}$ & \\
\hline Reference & $\begin{array}{c}\text { Type of substance } \\
\text { use }\end{array}$ & $\begin{array}{l}\text { Overall } \\
\text { cognition }\end{array}$ & Attention & $\begin{array}{l}\text { Executive } \\
\text { function }\end{array}$ & Memory & $\begin{array}{l}\text { Working } \\
\text { memory }\end{array}$ & $\begin{array}{l}\text { Verbal } \\
\text { function }\end{array}$ \\
\hline \multicolumn{8}{|l|}{ Substance use } \\
\hline Manning, Teo, Guo, Wong, \& Li (2016) & Alcohol & $\mathrm{X}$ & & $\sqrt{ }$ & $\sqrt{ }$ & $\sqrt{ }$ & \\
\hline Fisk \& Montgomery (2008) & Cannabis use & & & $\mathrm{X}$ & & & \\
\hline Parrott \& Kaye (1999) & Ecstasy use & & $\mathrm{X}$ & & $\mathrm{X}$ & & \\
\hline $\begin{array}{l}\text { Heffernan, Jarvis, Rodgers, Scholey, \& } \\
\text { Ling (2001) }\end{array}$ & Ecstasy use & & & & & & $\mathrm{X}$ \\
\hline Montgomery \& Fisk (2007) & Ecstasy-polydrug use & $\mathrm{X}$ & & $\mathrm{X}$ & & $\sqrt{ }$ & \\
\hline $\begin{array}{l}\text { Hadjiefthyvoulou, Fisk, Montgomery, \& } \\
\text { Bridges (2011) }\end{array}$ & Ecstasy-polydrug use & & & & $\mathrm{X}$ & & \\
\hline
\end{tabular}


COGNITIVE FAILURES, PSYCHOLOGICAL DISORDERS, SUBSTANCE USE

Notes: $\sqrt{ }$ Denotes domain compared with CFQ scores and association identified. X Denotes domain compared with CFQ scores but no association identified. Columns left blank donate domains of cognition not studied by the cited article. *Parity only met for patients with intact clinical insight. 
COGNITIVE FAILURES, PSYCHOLOGICAL DISORDERS, SUBSTANCE USE

\section{Figure captions}

Figure 1. Flow diagram of study selection for systematic review of published research on cognitive failures in populations with psychological disorders. 